\title{
Grand challenges in structural materials
}

\author{
John L. Provis * \\ Department of Materials Science and Engineering, University of Sheffield, Sheffield, UK \\ *Correspondence: j.provis@sheffield.ac.uk
}

Edited and reviewed by:

Wenhui Duan, Monash University, Australia

Keywords: structural materials, grand challenges, composites, multiscale modeling, sustainability

\section{INTRODUCTION}

The motto "citius, altius, fortius" (Latin for "faster, higher, stronger") is known worldwide in the context of the Olympic Games and could also be viewed - with the inevitable addition of "cheaper" - as the catch-cry of the structural materials industry throughout the nineteenth and twentieth centuries. Steel, concrete, wood, structural ceramics, glass, nonferrous metals, and a wide range of composites underpin the entirety of modern society. Taller and more ambitious structures placed in more extreme service environments demand materials with higher performance: strength, durability, and scope for repair and retrofitting in challenging environments. Rapid construction not only influences costs related to performance but also demands improved materials and manufacturing. The U.S. Materials Genome Initiative Strategic Plan lists "Lightweight and Structural Materials" to be of primary importance across sectors: national security, human health and welfare, clean energy systems, and infrastructure, and consumer goods (National Science and Technology Council Committee on Technology, 2014).

The goal of sustainability was added to the core ambitions of the structural materials industry around the beginning of the twenty-first century, as environmental footprints and resource depletion were better understood. As recently as 1999, the U.S. National Academy of Engineering published a report entitled "Structural Materials: Challenges and Opportunities" (Starke and Williams, 1999) without mentioning sustainability; from this point, we can observe a rapid shift in emphasis toward sustainable development objectives in less than two decades, where it would now be unthinkable to omit this aspect from a discussion of challenges in the science and engineering of structural materials.

Today, we are facing scientific and technological challenges linked to provision of durable and reliable infrastructure to the billions worldwide who live without appropriate housing, energy, and/or sanitation. Solutions here will not necessarily involve advanced structural materials as such, but will be related to optimizing structural characteristics and durability at low financial and environmental costs. This requires creativity to rely on locally available resources, which means that we should not always count on one-size-fits-all solutions. Modern materials design thus goes far beyond pure technical performance. To "do more with less" has given additional impetus to research on materials recycling, reuse, and substitution, including in the improvement of material durability.

The above goals can only be achieved through a thorough scientific approach to materials design that also exploits recent advances in high-throughput, combinatorial and computational methodologies in manufacturing, analytical and dataprocessing facilities. The result is that we are able to precisely specify almost all material characteristics for any given application.

The present article offers a summary of the key areas of research and challenges facing structural materials researchers with particular focus on areas with major advances to be made. This discussion is by no means exhaustive as the topic merits analysis in far more depth than is possible within the context of an overview article.

\section{BOTTOM-UP DESIGN OF MATERIALS FOR IMPROVED PROPERTIES}

The most dramatic innovations in new materials development are now being seen at the interfaces between apparently distinct fields of science, which are areas ripe for innovation. Such new materials are increasingly being designed, rather than just discovered. The development of metallic glasses with extremely high damage tolerance (Demetriou et al., 2011) or biomimetic structures engineered to produce composites with enhanced mechanical properties (Fratzl, 2007) provide excellent examples. The achievement of further innovations and improvements in material properties and performance will increasingly require a bottom-up design process that tailors properties at a chemical, a nanostructural, and a microstructural level. Thus, greater crosstalk is needed between the theoretical and practical aspects of the field of structural materials science.

The goals stated by the U.S. Materials Genome Initiative include the ambition to quantitatively predict the corrosion behavior of any metal alloy, and to describe the processes of polymer curing and structural damage to polymer composites (National Science and Technology Council Committee on Technology, 2014). Multiscale modeling is necessarily central to the description of such processes (Nieminen, 2002). In this context, there is an emerging demand, and an ongoing challenge, for materials specialists to collaborate with modelers to identify new "physical shortcuts" (Elliott, 2011), to overcome the problematic computational load associated with simulations on a realistic geometric scale, or describing "rare" events in dynamic simulations.

Processes of importance in concrete science span around 10 orders of magnitude in both length and time scales nanometers to centimeters, picoseconds to decades - and therefore it is far from straightforward to link atomistic-level properties to macroscopically observable 
ones (Jennings and Bullard, 2011). For example, we face a debate among the best existing models to explain the factors underlying the microstructural evolution of cement paste within the first $48 \mathrm{~h}$ after mixing (Thomas et al., 2011). It is a question that will certainly require major advances in the available theoretical approaches, as well as in improvement of the in situ and ex situ characterization methods to provide the data for model validation. This is not to say that the problem is intractable, but caution is certainly needed when using molecular-scale simulations to directly predict the macroscopic properties of a material, which is heterogeneous on every length scale, without also considering mesoscale interactions and influences.

A recent Grand Challenge article in another section of this journal provides an excellent overview of glass science (Mauro, 2014) to enable the full potential of glass as a structural and functional material. Focused research efforts, such as the Usable Glass Strength Coalition (Mattos, 2012), provide a framework for industry and academia to collaborate to identify and solve key problems in glass science, linking research to an end application. Industry may play a central role in inspiring cuttingedge basic research through provision of insight and facilities that allow academics to genuinely ask the right questions for future innovation.

\section{SUSTAINABLE SUPPLY: SOURCING, RECYCLING, AND DIVERSIFICATION}

Design engineers have long dreamed of implausible combinations of material properties, and have described such materials as "unobtainium" since at least the 1950s (Becker, 1983). We also face significant practical availability constraints on a number of key elements in modern materials engineering, which may arise due to geopolitical reasons or simply because global demand exceeds the available quantity of a particular element (European Commission, 2014). Among the materials on the 2014 EU Critical Raw Materials list, magnesium/magnesite, niobium, chromium, and tungsten are of interest in the structural materials sphere. Their substitution by other elements is significantly limited based on the current performance of their alternatives in their main applications (Graedel et al., 2013). Thus, the substitution of scarce or expensive components in structural materials without loss of essential performance is a key area of research at present, and is only likely to become more so in future years.

Supply constraints are actually not limited to costly or geologically scarce elements; the concrete industries in US and UK have in recent years experienced shortages of fly ash, a by-product of coal combustion for electricity. As the processes used for electricity generation change to improve environmental sustainability by low- $\mathrm{NO}_{\mathrm{x}}$ burners and a shift to biomass combustion, the characteristics of byproduced ashes are no longer ideal for use in concretes.

Further demand for alternative cementing systems is driven by the high environmental footprint of Portland cement itself, which contributes to around $8 \%$ of the global anthropogenic $\mathrm{CO}_{2}$ emissions. This comes from its carbon-intensive production from limestone precursors and is due to its extremely high production volumes, $>3$ billion tonnes per annum worldwide (Olivier et al., 2012). Some of these alternatives are based on the substitution of Portland cement itself by other materials (Juenger et al., 2011; Provis and Bernal, 2014), while others are based on the exploitation of natural clay mineral reserves calcined to enhance reactivity (Scrivener, 2014). In the long-term, a "toolkit" of various approaches will be used in cement design and selection, and the optimal solutions will differ between applications and geographical locations, depending on the local availability and costs of raw materials (Provis, 2014).

In this context, many important questions are raised about the sustainability characteristics of bulk structural materials. For example, discussion is open regarding the environmental merits of concrete vs. timber in structural applications (Purnell, 2011; Sathre et al., 2012), where critical issues in this debate relate to definitions of functional units, system boundaries, and attribution of emissions among co- and byproducts. Very different outcomes can be reached from superficially similar life-cycle analysis studies when scopes and attributions are defined in subtly different ways. Lobby groups promoting specific classes of materials, environmental scientists, policymakers, and economics experts together play a fundamental role in decision-making at both local and global levels, based on analysis which must be fundamentally rooted in local considerations.

The other key point related to the sustainable use of materials is that one of the pillars of sustainability is efficiency: the avoidance of wastage. The recycling or downcycling of off-cuts or scrap of traditional manufacturing, in particular, metals, textiles, and wood, introduces enormous energy costs. The percentage of metal machined or cut away and re-melted is commonly around $50 \%$, and can be as high as $90 \%$ where the product geometry is complex and its weight must be minimized (Allwood and Cullen, 2012). In the case of wood and many composites, the scrap is not recyclable in this way and is generally recovered into lower-value products or used as fuel.

The modern shift toward additive manufacturing (Gibson et al., 2015) can potentially reduce this degree of wastage. There are various issues that still require intensive research input for the process to be both optimized and fully reliable in all circumstances in its use for materials including metals, polymers, ceramics, cement, and concrete.

\section{MATERIALS FOR EXTREME SERVICE ENVIRONMENTS, AND THE IMPORTANCE OF DURABILITY IN GENERAL}

Several of the most extreme service environments on Earth are found within operating nuclear reactors. For this reason, intensive effort has been dedicated worldwide to the development of materials, which can withstand high operating temperatures, high irradiation dose rates, and contact with chemically aggressive fluids such as molten metals and metal halides (OECD Nuclear Energy Agency, 2013). As older reactors continue to undergo service extension programs (Naus, 2009), material properties need to be investigated under long-term irradiation, thermal and mechanical loading. Extended service life of a nuclear reactor component is imperative because repairs are complex, difficult, and expensive and the consequences of material failure can be dramatic. The materials challenges associated with both 
structural components of advanced fission reactor systems (OECD Nuclear Energy Agency, 2013) and future fusion reactors (Duffy, 2010) are further complicated by the inability to replicate key service environments in the laboratory; modeling and simulation approaches have thus become central to performance prediction.

Of course, the nuclear industry is far from the only scenario in which challenging service environments are experienced by structural materials. Cyclic loadsmechanical and thermal, including freezethaw processes - are particularly damaging to materials in applications ranging from aerospace to residential construction, and the effects of long-term static load are also far from completely understood. Multidecadal creep of concrete causes severe deflection, and occasionally collapse, in bridges (Wendner et al., 2014); however, it is rarely able to be measured in the laboratory due to the very long timescales involved.

A material must be durable to be considered truly sustainable, i.e., it should retain its desired properties and appearance at least for the span of its intended service life. Durability is a critical point to consider when proposing the replacement of a material with a "low-carbon" alternative, as the environmental and financial costs of repair, retrofitting, or replacement also need to be incorporated into the cost-benefit analysis. The need for resilience and durability as a performance criterion has also led to the suggestion that toughness rather than strength should be used as the key in materials selection, as this is often a limiting factor in service (Launey and Ritchie, 2009). It is clear that a more nuanced view of the mechanical performance of materials and its dependence on time, environmental, and mechanical loads, is warranted in the field of structural materials in general; it will no longer be sufficient to specify a material according to a single strength measurement, whether compressive or tensile, if complex physical and chemical loading states are expected during its service life.

\section{CONCLUDING REMARKS}

Upon launching a new journal in this highly active research field, it is always tempting to make grand predictions regarding the future directions. The quote "prediction is very difficult, especially about the future" - attributed variously (and maybe erroneously) to Niels Bohr, Yogi Berra, and others - seems eminently relevant in this context. The one thing of which we can be certain is that structural materials will be revolutionized in the coming years by advances in computational capabilities, by deeper interactions with other branches of engineering and science, and by the application of thousands of talented minds to the solutions of problems facing global society. Major leaps forward in the understanding and use of structural materials lie at the interfaces between research disciplines - physics, chemistry, chemical engineering geology, biology, mechanical engineering, civil engineering, architecture, industrial design, and industrial/process engineering, to name a few. These areas bring a range of perspectives that structural materials researchers can use to broaden our view on critical problems.

How can we enable sustainable, safe, durable, and resilient provision of housing, infrastructure, energy, and transport to the growing global population? If the whole planet is made of "stuff," then the scientists and engineers of structural materials are the ones who convert that "stuff" into a useful form, and enable our society to be built upon it. The grandest challenge of all is therefore not just to conduct research, but to implement its results for the benefit of the entire society.

\section{ACKNOWLEDGMENTS}

The insightful comments of Dr. Susan A. Bernal in the drafting of this paper, and the editorial input of Dr. Anna Lukacs, are gratefully appreciated.

\section{REFERENCES}

Allwood, J. M., and Cullen, J. M. (2012). Sustainable Materials with Both Eyes Open. Cambridge: UIT.

Becker, J. V. (1983). The Development of Winged Reentry Vehicles, 1952-1963. NASA. Available at: http://crgis.ndc.nasa.gov/crgis/images/5/5f/ Becker1983.pdf

Demetriou, M. D., Launey, M. E., Garrett, G., Schramm, J. P., Hofmann, D. C., Johnson, W. L., et al. (2011). A damage-tolerant glass. Nat. Mater. 10, 123-128. doi:10.1038/nmat2930

Duffy, D. M. (2010). Fusion power: a challenge for materials science. Philos. Trans. A Math. Phys. Eng. Sci. 368, 3315-3328. doi:10.1098/rsta.2010. 0060

Elliott, J. A. (2011). Novel approaches to multiscale modelling in materials science. Int. Mater. Rev. 56, 207-225. doi:10.1179/1743280410Y.0000000002
European Commission. (2014). Report on Critical Raw Materials for the EU: Report of the Ad hoc Working Group on Defining Critical Raw Materials. Brussels: European Commission, 41.

Fratzl, P. (2007). Biomimetic materials research: what can we really learn from nature's structural materials? J. R. Soc. Interface 4, 637-642. doi:10.1098/rsif. 2007.0218

Gibson, I., Rosen, D. W., and Stucker, B. (2015). Additive Manufacturing Technologies: Rapid Prototyping to Direct Digital Manufacturing, 2nd Edn. New York, NY: Springer.

Graedel, T. E., Harper, E. M., Nassar, N. T., and Reck, B. K. (2013). On the materials basis of modern society. Proc. Natl. Acad. Sci. U.S.A. doi:10.1073/pnas. 1312752110

Jennings, H. M., and Bullard, J. W. (2011). From electrons to infrastructure: engineering concrete from the bottom up. Cem. Concr. Res. 41, 727-735. doi:10.1016/j.cemconres.2011.03.025

Juenger, M. C. G., Winnefeld, F., Provis, J. L., and Ideker, J. (2011). Advances in alternative cementitious binders. Cem. Concr. Res. 41, 1232-1243. doi:10.1016/j.cemconres.2010.11.012

Launey, M. E., and Ritchie, R. O. (2009). On the fracture toughness of advanced materials. Adv. Mater. 21, 2103-2110. doi:10.1002/adma.200803322

Mattos, L. (2012). Usable glass strength coalition: patience, perseverance and progress. Am. Ceram. Soc. Bull. 91, 22-29.

Mauro, J. C. (2014). Grand challenges in glass science. Front. Mater. 1:20. doi:10.3389/fmats.2014. 00020

National Science and Technology Council Committee on Technology. (2014). Materials Genome Initiative Strategic Plan. Washington, DC: Executive Office of the President of the United States of America. Available at: http://www.whitehouse.gov/sites/ default/files/microsites/ostp/NSTC/mgi_strategic plan_-_dec_2014.pdf

Naus, D. J. (2009). The management of aging in nuclear power plant concrete structures. JOM 61, 35-41. doi:10.1007/s11837-009-0100-0

Nieminen, R. M. (2002). From atomistic simulation towards multiscale modelling of materials. J. Phys Condens. Matter 14, 2859-2876. doi:10.1088/09538984/14/11/306

OECD Nuclear Energy Agency. (2013). Status Report on Structural Materials for Advanced Nuclear Systems. Paris: OECD.

Olivier, J. G. J., Janssens-Maenhout, G., and Peters, J. A. H.W. (2012). Trends in Global $\mathrm{CO}_{2}$ Emissions; 2012 Report. Hague: PBL Netherlands Environmental Assessment Agency, 40.

Provis, J. L. (2014). Green concrete or red herring? Future of alkali-activated materials. Adv. Appl. Ceram. 113, 472-477. doi:10.1179/1743676114Y. 0000000177

Provis, J. L., and Bernal, S. A. (2014). Geopolymers and related alkali-activated materials. Annu. Rev. Mater. Res. 44, 299-327. doi:10.1146/annurevmatsci-070813-113515

Purnell, P. (2011). Material nature versus structural nurture: the embodied carbon of fundamental structural elements. Environ. Sci. Technol. 46, 454-461. doi:10.1021/es202190r

Sathre, R., Dodoo, A., Gustavsson, L., Lippke, B., Marland, G., Masanet, E., et al. (2012). Comment on "material nature versus structural nurture: the 
embodied carbon of fundamental structural elements". Environ. Sci. Technol. 46, 3595-3596. doi: 10.1021/es300276b

Scrivener, K. (2014). Options for the future of cement. Indian Concr. J. 88, 11-21.

Starke, E. A., and Williams, J. C. (1999). Structural materials: challenges and opportunities. Bridge (Natl. Acad. Eng.) 29, 25-31.

Thomas, J. J., Biernacki, J. J., Bullard, J. W., Bishnoi, S., Dolado, J. S., Scherer, G. W., et al. (2011). Modeling and simulation of cement hydration kinetics and microstructure development. Cem. Concr. Res. 41, 1257-1278. doi:10.1016/j.cemconres.2010. 10.004
Wendner, R., Hubler, M. H., and Bažant, Z. P. (2014). "Model B4: multi-decade creep and shrinkage prediction of traditional and modern concretes," in Computational Modelling of Concrete Structures Proceedings of EURO-C 2014 (St Anton im Arlberg: Taylor \& Francis), 679-684.

Conflict of Interest Statement: The author declares that the research was conducted in the absence of any commercial or financial relationships that could be construed as a potential conflict of interest.

Received: 11 March 2015; accepted: 25 March 2015; published online: 08 April 2015.
Citation: Provis JL (2015) Grand challenges in structural materials. Front. Mater. 2:31. doi: 10.3389/fmats.2015.00031

This article was submitted to Structural Materials, a section of the journal Frontiers in Materials.

Copyright $\odot 2015$ Provis. This is an open-access article distributed under the terms of the Creative Commons Attribution License (CC BY). The use, distribution or reproduction in other forums is permitted, provided the original author(s) or licensor are credited and that the original publication in this journal is cited, in accordance with accepted academic practice. No use, distribution or reproduction is permitted which does not comply with these terms. 